\title{
Sliding Mode Control of Bi-directional DC/DC Converter in DC Microgrid Based on Exact Feedback Linearization
}

\author{
LIHUA WANG, TIANZE MIAO, XIAONA LIU, SIYUAN LIU \\ College of Electronic and Information Engineering \\ Shandong University of Science and Technology \\ No. 579 Qianwangang Road, Huangdao District, Qingdao, 266590 \\ CHINA
}

\begin{abstract}
The nonlinear property of bi-directional DC/DC converter in DC Microgrid will cause large voltage disturbance. To solve the above problems, a exact feedback linearization method based on nonlinear differential geometry theory is proposed to realize the linearization of the converter. Moreover, considering the approaching speed of the linearized Bruno standard model, a sliding mode controller is designed by using the exponential approach law. The simulation results show that the method has fast response speed, strong anti- interference ability and good steady-state characteristics.
\end{abstract}

Key-Words: - bi-directional DC/DC converter, exact feedback linearization, sliding mode controller

Received: March 24, 2020. Revised: September 5, 2020, Accepted: September 25, 2020. Published: October 6, 2020.

\section{Introduction}

The bi-directional DC/DC converter is a typical nonlinear system, and linear control method applied in this kind of system has great limitations, so it is the trend now, to apply nonlinear control method to bidirectional DC/DC converter. Such as PID control method, differential geometry method and backstepping control method. Exact feedback linearization is a common method in nonlinear applications of $\mathrm{DC} / \mathrm{DC}$ converters, which has attracted the attention of some researchers due to its high precision[1-3]. The core of this method is to make the nonlinear system realize the precise linearization of state or input/output through the appropriate nonlinear state and coordinate transformation, so as to transform the complex nonlinear system comprehensive problem into the comprehensive problem of linear system[4-5]. In the process of linearization, the higher-order nonlinear terms are not ignored, therefore this linearization is accurate and can be applied to the whole region defined by linearization. This method has been successfully used to solve some practical control problems. In literatures[6-7], the linear control method of exact feedback linearization is applied to the control of bi-directional DC/DC converter,and a rather satisfactory effect is achieved, which also provides the possibility for the application of this method in more complex power electronic systems.In literature[8],Based on the analysis of the negative impedance characteristics of constant power load, a feedforward control strategy is proposed to counteract the influence of negative impedance characteristics on DC bus voltage, but the analysis is limited to small disturbance. The large signal model of the system is established in literature[9], which reflects the nonlinear problem of the system. However, the proposed control method does not solve the problem of system control variables. It is only applicable to SPS control and has limited application range.

The exact feedback linearization nonlinear control method in power electronics is based on the mathematical model of the nonlinear system, which does not consider the uncertainty of the real system, so its robustness is not strong. The sliding mode control method has a strong robustness to the external disturbances. And it has been widely used in all kinds of power electronic converters because of its inherent switching characteristics[10-12]. In literature[13], taking a two-stage boost converter as an example, adaptive global sliding mode control is adopted to ensure the stability of the system. In literature[14], for the non-linear quantization system whose state cannot be measured, the finite time tracking problem is solved, and the finite time quantitative feedback control is considered for the first time. In literature[15], a fuzzy sliding mode PI control method is designed for PMSM, the transition between sliding mode control and PI control is realized by fuzzy control, Some relevant studies can be found in [16] and [17]. In literature[18], the feedback linearization theory is used to decouple the speed and d-axis current of PMSM, and the sliding 
mode control method with double power approach law is introduced to improve the robustness of the control system.

Based on the inspiration of the above papers, in order to improve the anti-interference ability of the DC bus voltage of the microgrid, a feedback linearization sliding mode variable structure control method is proposed.

\section{Linearization of Converters}

The bidirectional Buck-Boost converter using complementary conduction method, As shown in Fig. 1, in which $S_{1}$ is ON while $S_{2}$ is OFF, on the contrary, it is shown in Fig. 2. Compared with the independent conductance mode, this method does not need logic parts to switch Buck and Boost circuits, which improves the working efficiency.

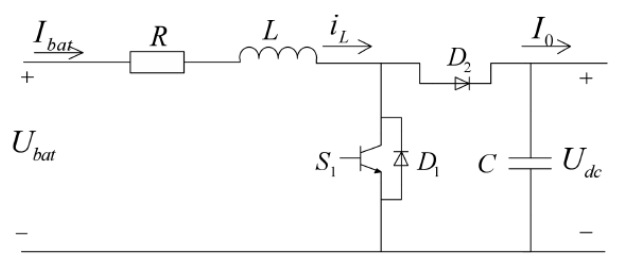

Fig. 1 Phase 1 schematic diagram

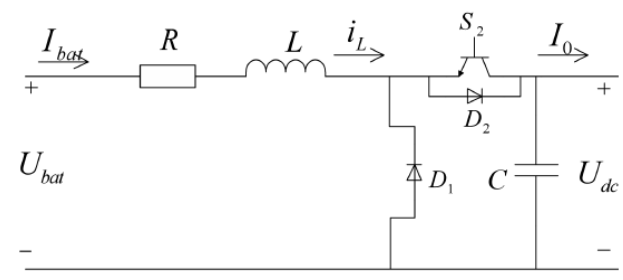

Fig. 2 Phase 2 schematic diagram

Phase 1, where $S_{1}$ is ON while $S_{2}$ is OFF, is the work phase of the Boost converter, in which the average equation of state-space of the system is shown in Equation (1):

$$
\left\{\begin{array}{c}
\mathrm{L} \frac{\mathrm{di}_{\mathrm{L}}}{\mathrm{dt}}=\mathrm{U}_{\mathrm{bat}}-\mathrm{Ri}_{\mathrm{L}} \\
\mathrm{C} \frac{\mathrm{dU} \mathrm{dc}}{\mathrm{dt}}=-\mathrm{I}_{0}
\end{array}\right.
$$

And phase 2, where $S_{2}$ is ON while $S_{1}$ is OFF, is the work phase of the Buck converter, in which the average equation of state-space of the system is shown in Equation (2):

$$
\left\{\begin{array}{c}
\mathrm{L} \frac{\mathrm{di}_{\mathrm{L}}}{\mathrm{dt}}=\mathrm{U}_{\mathrm{bat}}-\mathrm{Ri}_{\mathrm{L}}-\mathrm{U}_{\mathrm{dc}} \\
\mathrm{C} \frac{\mathrm{dU_{ \textrm {dc } }}}{\mathrm{dt}}=\mathrm{i}_{\mathrm{L}}-\mathrm{I}_{0}
\end{array}\right.
$$

If $\mathrm{x}$ equals $\left[\begin{array}{ll}\mathrm{U}_{\mathrm{dc}} & \mathrm{i}_{\mathrm{L}}\end{array}\right]^{\mathrm{T}}$ and $\mathrm{u}$ equals $\left[\begin{array}{ll}\mathrm{I}_{0} & \mathrm{U}_{\mathrm{bat}}\end{array}\right]^{\mathrm{T}}$, State-space model is given by:

$$
\begin{gathered}
\dot{\mathrm{x}}_{1}=\mathrm{A}_{1} \mathrm{x}+\mathrm{B}_{1} \mathrm{u}=\left[\begin{array}{cc}
0 & 0 \\
0 & -\frac{\mathrm{R}}{\mathrm{L}}
\end{array}\right]\left[\begin{array}{cc}
\mathrm{U}_{\mathrm{dc}} \\
\mathrm{i}_{\mathrm{L}}
\end{array}\right]+\left[\begin{array}{cc}
-\frac{1}{\mathrm{C}} & 0 \\
0 & \frac{1}{\mathrm{~L}}
\end{array}\right]{ }_{\mathrm{U}_{\text {bat }}}^{\mathrm{I}_{0}} \\
\dot{\mathrm{x}}_{2}=\mathrm{A}_{2} \mathrm{X}+\mathrm{B}_{2} \mathrm{u}=\left[\begin{array}{cc}
0 & \frac{1}{\mathrm{C}} \\
-\frac{1}{\mathrm{~L}} & -\frac{\mathrm{R}}{\mathrm{L}}
\end{array}\right]\left[\begin{array}{cc}
\mathrm{U}_{\mathrm{dc}} \\
\mathrm{i}_{\mathrm{L}}
\end{array}\right]+\left[\begin{array}{cc}
-\frac{1}{\mathrm{C}} & 0 \\
0 & \frac{1}{\mathrm{~L}}
\end{array}\right]\left[\begin{array}{c}
\mathrm{I}_{\mathrm{U}_{\text {bat }}} \\
\mathrm{I}_{\text {b }}
\end{array}\right]
\end{gathered}
$$

Assuming that the duty cycle when $\mathrm{S}_{1}$ is $\mathrm{ON}$ is $d$, then the duty cycle when $\mathrm{S}_{2}$ is $\mathrm{ON}$ is $1-d$, Substituting Equations (3) and (4), we get:

$$
\begin{aligned}
& \left.\dot{\mathrm{x}}=\left[\mathrm{dA}_{1}+(1-\mathrm{d}) \mathrm{A}_{2}\right] \mathrm{x}+\left[\mathrm{dB}_{1}+\mathrm{g} 1-\mathrm{d}\right) \mathrm{B}_{2}\right] \mathrm{u} \\
& \left.=\left[\begin{array}{cc}
0 & \frac{1-\mathrm{d}}{\mathrm{C}} \\
-\frac{1-\mathrm{d}}{\mathrm{L}} & -\frac{\mathrm{R}}{\mathrm{L}}
\end{array}\right]\left[\begin{array}{cc}
\mathrm{U}_{\mathrm{dc}} \\
\mathrm{i}_{\mathrm{L}}
\end{array}\right]+\left[\begin{array}{cc}
-\frac{1}{\mathrm{C}} & 0 \\
0 & \frac{1}{\mathrm{~L}}
\end{array}\right]{ }_{\mathrm{U}_{\text {bat }}}^{\mathrm{I}_{0}}\right]
\end{aligned}
$$

The transfer function of output voltage $\mathrm{U}_{\mathrm{dc}}$ and duty cycle $d$ of bi-directional Buck-Boost converter is a non minimum phase system. If $U_{d c}$ in the converter is used as the output of the control system, the converter transfer function is thereby the minimum phase system. Therefore, the state space equation of the converter can be expressed as the following affine linear standard equation:

$$
\left\{\begin{array}{c}
\dot{X}=f(x)+g(x) u \\
y=h(x)=x_{2}-U_{\text {ref }}
\end{array}\right.
$$

In Equation(6), $\mathrm{x}=\left[\mathrm{x}_{1} \mathrm{x}_{2}\right]^{\mathrm{T}}=\left[\mathrm{i}_{\mathrm{L}} \mathrm{U}_{\mathrm{dc}}\right]^{\mathrm{T}}$ is the state variable, $f(x)=\left[\frac{U_{\text {bat }}}{\mathrm{L}}-\frac{\mathrm{x}_{2}}{\mathrm{~L}} \frac{\mathrm{x}_{1}}{\mathrm{C}}-\frac{\mathrm{x}_{2}}{\mathrm{CR}}-\frac{\mathrm{P}}{\mathrm{Cx}_{2}}\right]^{\mathrm{T}}, \mathrm{g}(\mathrm{x})=$ $\left[\frac{\mathrm{x}_{2}}{\mathrm{~L}}-\frac{\mathrm{x}_{1}}{\mathrm{C}}\right]^{\mathrm{T}}, \mathrm{u}=\mathrm{d}$, as the duty cycle, are the control variable, $y$ is the output and $U_{\text {ref }}$ is the reference value of bus voltage.

According to the requirements of exact feedback linearization, the output function $\mathrm{y}=\mathrm{x}_{2}-\mathrm{U}_{\mathrm{ref}}$ defined by Equation (6) cannot achieve feedback linearization of the system through coordinate transformation [15], so it is necessary to reconstruct a new output function $y=\omega(X)$ to satisfy the requirement that the relative degree $r$ of the system is equal to the system dimension. For this reason, $\omega(\mathrm{X})$ must satisfy the following equation:

$$
\mathrm{L}_{\mathrm{g}} \omega(\mathrm{X})=\frac{\partial \omega(\mathrm{X})}{\partial \mathrm{X}} \mathrm{g}(\mathrm{X})=0
$$

Chose new state variables as follows: 


$$
\omega(X)=\frac{1}{2} \mathrm{Lx}_{1}^{2}+\frac{1}{2} \mathrm{Cx}_{2}^{2}
$$

It can be seen from the above equation that: the defined output function is the total energy storage of bidirectional Buck-Boost converter, which provides a clear physical basis for the control method. According to the calculated $\omega(\mathrm{X})$, it can be calculated:

$$
\begin{gathered}
\mathrm{L}_{\mathrm{f}} \omega(\mathrm{x})=\frac{\partial \omega(\mathrm{X})}{\partial \mathrm{X}} \mathrm{f}(\mathrm{X})=\mathrm{U}_{\mathrm{bat}} \mathrm{X}_{1}-\frac{\mathrm{x}_{2}^{2}}{\mathrm{R}}-\mathrm{P} \\
\mathrm{L}_{\mathrm{g}} \mathrm{L}_{\mathrm{f}} \omega(\mathrm{x})=\frac{\partial \mathrm{L}_{\mathrm{f}} \omega(\mathrm{X})}{\partial \mathrm{X}} \mathrm{g}(\mathrm{X})=\frac{\mathrm{U}_{\mathrm{bat}} \mathrm{X}_{2}}{\mathrm{~L}}+\frac{2 \mathrm{x}_{1} \mathrm{X}_{2}}{\mathrm{CR}}(10) \\
\mathrm{L}_{\mathrm{f}}^{2} \omega(\mathrm{x})=\frac{\partial \mathrm{L}_{\mathrm{f}} \omega(\mathrm{X})}{\partial \mathrm{X}} \mathrm{f}(\mathrm{X})=\frac{\mathrm{U}_{\mathrm{bat}}{ }^{2}}{\mathrm{~L}}-\frac{\mathrm{U}_{\mathrm{bat}} \mathrm{x}_{2}}{\mathrm{~L}}+\frac{2 \mathrm{x}_{2}^{2}}{\mathrm{CR}^{2}}+\frac{2 \mathrm{P}}{\mathrm{CR}}
\end{gathered}
$$
as:

Coordinate transformation could be conducted

$$
\left\{\begin{array}{c}
\mathrm{Z}_{1}=\frac{1}{2} \mathrm{Lx}_{1}^{2}+\frac{1}{2} \mathrm{Cx}_{2}^{2} \\
\mathrm{Z}_{2}=\mathrm{U}_{\mathrm{bat}} \mathrm{X}_{1}-\frac{\mathrm{x}_{2}^{2}}{\mathrm{R}}-\mathrm{P}
\end{array}\right.
$$

After coordinately transferred, the nonlinear system turns into the Brunovsky standard type:

$$
\left\{\begin{array}{c}
\dot{\mathrm{z}}_{1}=\mathrm{Z}_{2} \\
\dot{\mathrm{z}}_{2}=\mathrm{v}
\end{array}\right.
$$

Then the relation between the new control variable $\mathrm{v}$ and the original control variable of the system is as follows:

$$
\mathrm{U}=\frac{-\mathrm{L}_{\mathrm{f}}^{2} \omega(\mathrm{x})+\mathrm{v}}{\mathrm{L}_{\mathrm{g}} \mathrm{L}_{\mathrm{f}} \omega(\mathrm{x})}
$$

\section{Design of Sliding Mode Variable Structure Controller}

The biggest difference between sliding mode control and other control methods is that the structure of the system is not fixed, and it is always in dynamic change. Moreover, according to the current state of the system, the system can change purposefully, forcing the system to move according to the predetermined state trajectory of sliding mode. Sliding mode control can force the system to make small amplitude and high frequency up and down motion along the prescribed trajectory under certain characteristics. At the same time, this sliding mode can be designed and has nothing to do with system parameters and disturbances. Therefore, the system in sliding mode motion has good robustness. Bidirectional DC / DC converter is a second-order system. Firstly, the tracking error is studied.

$$
\left\{\begin{array}{c}
\mathrm{e}_{1}=\mathrm{Z}_{1}-\mathrm{Z}_{\mathrm{ref}} \\
\dot{\mathrm{e}_{1}}=\dot{\mathrm{Z}}_{1}-\dot{\mathrm{Z}}_{\mathrm{ref}}=\mathrm{Z}_{2}-\dot{\mathrm{Z}}_{\mathrm{ref}}
\end{array}\right.
$$

With $\mathrm{e}_{1}$ being the tracking error and $\mathrm{Z}_{\mathrm{ref}}$, the reference of $Z_{1}$, the first Lyapunov functions is defined as:

$$
\mathrm{V}_{1}=\frac{1}{2} \mathrm{e}_{1}^{2}
$$

Take a derivation with respect to Equation (16) and Substituting Equations (15), we get:

$$
\dot{\mathrm{V}}_{1}=\mathrm{e}_{1} \dot{\mathrm{e}}_{1}=\mathrm{e}_{1}\left(\mathrm{Z}_{2}-\dot{\mathrm{Z}}_{\mathrm{ref}}\right)
$$

The virtual control amount of the variable subsystem is set as:

$$
\mathrm{e}_{2}=\mathrm{Z}_{2}-\dot{\mathrm{Z}}_{\mathrm{ref}}+\mathrm{c}_{1} \mathrm{e}_{1}
$$

Substituting Equation (17) can be represented:

$$
\dot{\mathrm{V}}_{1}=\mathrm{e}_{1} \dot{\mathrm{e}}_{1}=\mathrm{e}_{1}\left(\mathrm{Z}_{2}-\dot{\mathrm{Z}}_{\mathrm{ref}}\right)=\mathrm{e}_{1} \mathrm{e}_{2}-\mathrm{c}_{1} \mathrm{e}_{1}^{2}
$$

Therefore, if $\mathrm{e}_{2}=0$, then $\dot{V}_{1} \leq 0$, so we have to do the second Lyapunov function to make $e_{2}$ infinitely close to 0 .

The second Lyapunov function is defined as:

$$
\mathrm{V}_{2}=\mathrm{V}_{1}+\frac{1}{2} \mathrm{e}_{2}^{2}
$$

Derivation of Equation (20):

$$
\dot{\mathrm{V}}_{2}=\dot{\mathrm{V}}_{1}+\mathrm{e}_{2} \dot{\mathrm{e}}_{2}
$$

Substituting Equations (13) and (14) in to Equation (18), we get:

$$
\begin{aligned}
& \mathrm{e}_{2}=\mathrm{v}+\mathrm{c}_{1} \dot{\mathrm{m}}_{1}-\ddot{\mathrm{Z}}_{\mathrm{ref}} \\
& \quad=\mathrm{L}_{\mathrm{f}}^{2} \omega(\mathrm{x})+\mathrm{L}_{\mathrm{g}} \mathrm{L}_{\mathrm{f}} \omega(\mathrm{x}) \mathrm{U}+\mathrm{c}_{1} \dot{\mathrm{e}}_{1}-\ddot{\mathrm{Z}}_{\mathrm{ref}}
\end{aligned}
$$

Substituting Equation (22) in to Equation (21):

$$
\begin{gathered}
\dot{\mathrm{V}}_{2}=\dot{\mathrm{V}}_{1}+\mathrm{e}_{2} \dot{\mathrm{e}}_{2}=\mathrm{e}_{1} \mathrm{e}_{2}-\mathrm{c}_{1} \mathrm{e}_{1}^{2}+ \\
+\mathrm{e}_{2}\left(\mathrm{~L}_{\mathrm{f}}^{2} \omega(\mathrm{x})+\mathrm{L}_{\mathrm{g}} \mathrm{L}_{\mathrm{f}} \omega(\mathrm{x}) \mathrm{U}+\mathrm{c}_{1} \dot{\mathrm{e}}_{1}-\ddot{\mathrm{Z}}_{\mathrm{ref}}\right)
\end{gathered}
$$

Therefore, the sliding mode plane can be represented as:

$$
\mathrm{S}=\mathrm{e}_{2}
$$


The exponential approach rate selected by sliding mode approach rate selects as:

$$
\dot{s}=-\varepsilon \operatorname{sgn}(\mathrm{s})-\mathrm{Ks}
$$

According to Equations (23), (24) and (25), the selected control rate $\mathrm{U}$ is:

$$
\mathrm{U}=\frac{-\mathrm{L}_{\mathrm{f}}^{2} \omega(\mathrm{x})-\mathrm{c}_{1} \dot{\mathrm{e}}_{1}+\ddot{Z}_{\mathrm{ref}}-\mathrm{e}_{1}-\varepsilon \operatorname{sgn}(\mathrm{s})-\mathrm{ks}}{\mathrm{Lg}_{\mathrm{f}} \omega(\mathrm{x})}
$$

Substituting Equation (26) in to Equation (23):

$$
\dot{\mathrm{V}}_{2}=-\mathrm{c}_{1} \mathrm{e}_{1}^{2}-\mathrm{ke}_{2}^{2}-\varepsilon\left|\mathrm{e}_{2}\right| \leq 0
$$

In summary, the system composed of equations (14) and (26) is asymptotically stable, and the design block diagram is shown in Fig. 3.

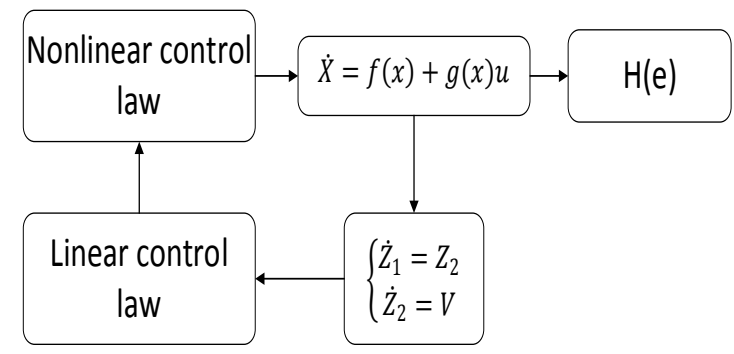

Fig. 3 General block diagram of exact feedback linearization

The voltage outer loop can be designed as a linear controller. The output of the outer loop controller is the reference value $U_{\text {ref }}$ of the capacitance voltage. Moreover, Using PI outer loop controller with certain robustness. Updated diagram is as Fig.4.

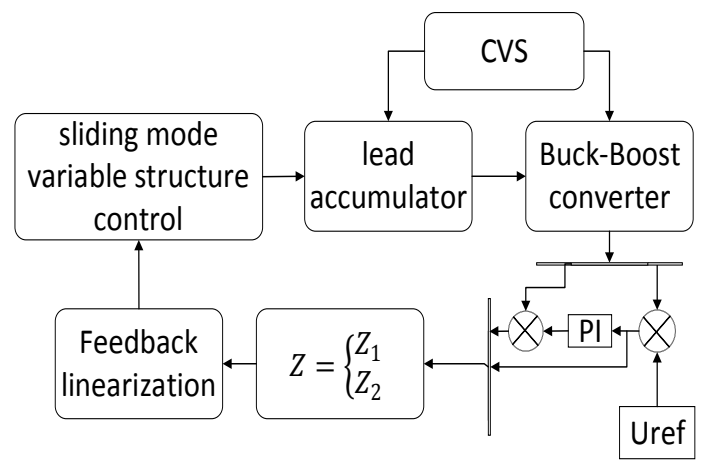

Fig. 4 sliding mode control network block diagram

\section{Simulation Analysis}

\subsection{System Parameter Design}

To verify the effectiveness of the converter control method in the DC microgrid, a sliding mode variable structure bidirectional Buck-Boost converter simulation model based on exact feedback linearization is established. Among them, the rated capacity of the battery is $10 \mathrm{Ah}$, the standard voltage is $400 \mathrm{v}$, the resistance $\mathrm{R}$ is $30 \Omega$, the inductance $\mathrm{L}$ is $0.001 \mathrm{H}$, and the capacitance $\mathrm{C}$ is $0.01 \mathrm{~F}$. The simulation results are compared with the conventional PI control. The PI control is selected by the critical proportional scale method, take $K_{P}$ $=1, K_{I}=30$. The load transient response is shown in Fig. 5.

\subsection{Response Characteristic}

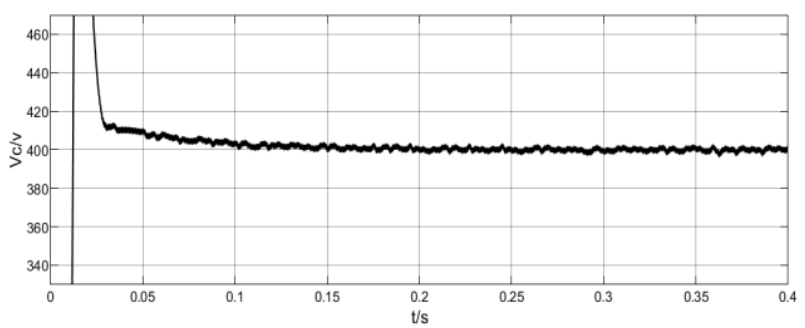

Fig. 5 (a) (b) is the bus voltage transient response

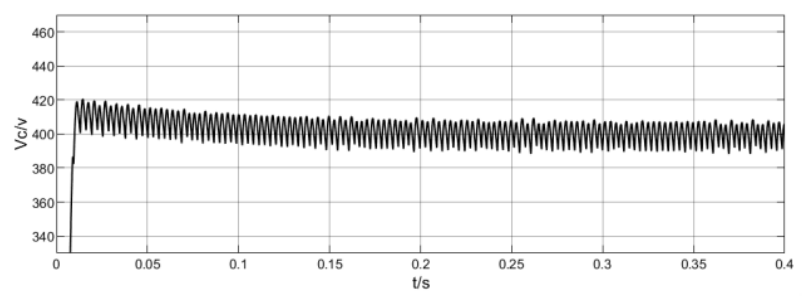

diagram of the two methods, and the set time is 0 $0.4 \mathrm{~S}$.

(a) Precise optimization control

(b) Traditional PI control

Fig. 5 Bus voltage transient response diagram

It can be seen from Fig. 5 that during the startup phase of the battery network structure, the bus voltage after the optimization has been optimized has a shorter response time than the bus voltage controlled by the traditional PI, can enter the steady state faster, and has less ripple.

\subsection{System Disturbance Change}

Figure 6-8 shows the waveform of each port during the charging and discharging process of the system. The time period is $0-2 \mathrm{~s}$ 


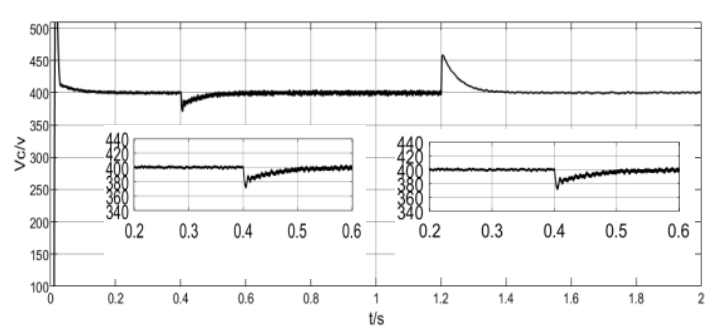

(a) Precise optimization control

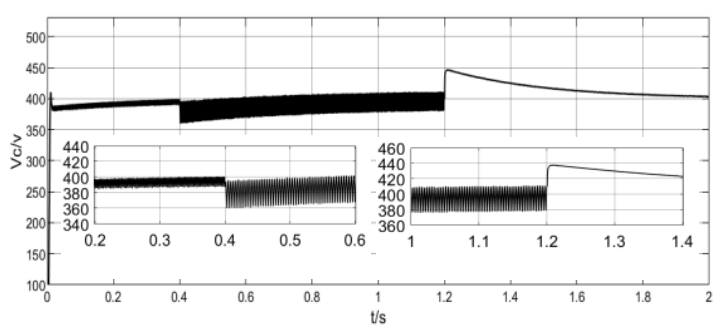

(b) Traditional PI control

Fig. 6 Comparison of bus voltage waveforms

Figure 6 shows the DC bus voltage waveform change graph. It can be seen that at $\mathrm{t}=0.4 \mathrm{~s}$, the load characteristic becomes the consumption of battery power. Figure 6(a) can react faster according to external changes, the steady-state effect is achieved at $0.49 \mathrm{~s}$, It can be seen from the local enlarged diagram that the voltage change is very small and the system is very stable in the steady state. After the bus returns to the standard $400 \mathrm{v}$, it has remained stable. At $1.2 \mathrm{~S}$, the load characteristics are converted to charge the battery and quickly reach the standard voltage. Compared with the traditional PI control, the anti-interference ability is better.

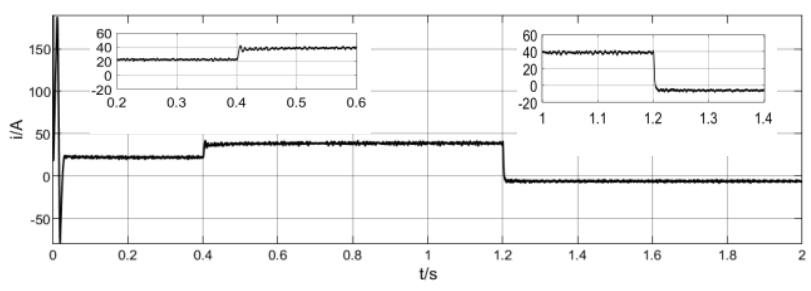

(a) Precise optimization control

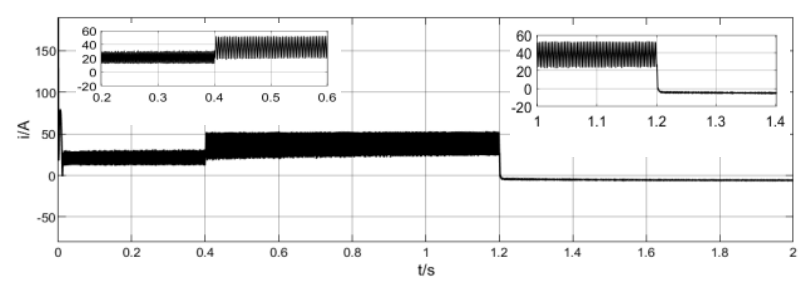

(b) Traditional PI control

Fig. 7 Comparison of inductor current waveforms
Figure 7 is a graph of inductor current waveform changes. The battery discharges before $1.2 \mathrm{~s}$. It can be found that the accurately optimized current ripple of Fig. 7 (a) is more stable, and the battery enters the charging state after 1.2s. By comparison, it is found that the optimized control system of Fig. 7 (a) can react quickly according to changes in the outside world.

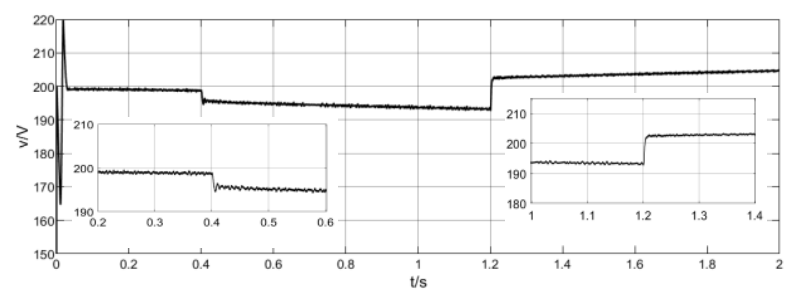

(a)Precise optimization control

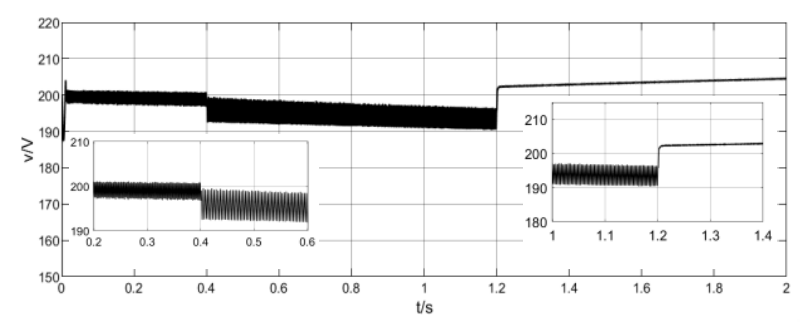

(b)Traditional PI control

Fig. 8 Comparison of battery voltage changes

The terminal voltage change curve at both ends of the battery is reflected in Fig. 8. When the voltage at both ends of the battery decreases, the time is consistent with the set controlled voltage source. At $0.4 \mathrm{~S}$, the battery enters the discharge process, after an optimized control system. It can enter the steady-state effect at $0.425 \mathrm{~S}$. In the local enlarged diagram, after the voltage changes, it is found that the system oscillation times of scheme a in Fig. 8(a) is less, and the voltage change is close to a straight line in steady state, which can enter the expected voltage value faster. Fig. 8(b) has not been able to achieve a good steady-state effect. The comparison shows that this control method has good robustness.

\section{Conclusion}

In the DC microgrid, combined with the existing precise feedback linearization control method and the traditional PID control method, aiming at the nonlinear characteristics of bidirectional DC / DC converter, based on the precise feedback linearization of the converter, the sliding mode control technology is introduced into the traditional 
PID feedback control technology, and the sliding mode variable structure controller is established.

Matlab / Simulink simulation results show that when the external conditions of the system change, especially in the process of lead-acid battery charging and discharging, the control method in this paper is helpful to improve the response speed and robustness of the system. Compared with the traditional PID feedback model, the sliding mode control method has better dynamic response regulation characteristics and steady-state error regulation characteristics, and has stronger robustness.

\section{Acknowledgments}

This work was supported by the Natural Science Foundation of Shandong Province, China (no. ZR2018MF005).

References:

[1] I. Alberto, Nonlinear Control Systems II, Publishing House of Electronics Industry, 2012

[2] Q. Lu, Y. Z. Sun, S. W. Mei, Nonlinear control of power system, Tsinghua University Press, 2008.

[3] Y. M. Hu, Theory and Application of Nonlinear Control System, National Defense Industry Press, 2005.

[4] L. L. Chen, C. S. Zhu, Z. X. Zhong and C. K. Wang, Radial Position Control for Magnetically Suspended High-speed Flywheel Energy Storage System with Inverse System Method and Extended 2-DOF PID Controller, IET Electric Power Applications, Vol.14, No.1, 2020, pp. 71-81.

[5] J. L. Li, S. Tian, Small-Gain Technique-Based Adaptive NN Control for Switched PureFeedback Nonlinear Systems, IEEE Transactions on Cybernetics, Vol.49, No.5, 2019, pp. 1873-1884.

[6] I. Gian, R. Matteo, F. antonella, Sliding Mode Control of Constrained Nonlinear Systems, IEEE Transactions on Automatic Control, Vol.62, No.6, 2017, pp. 2965-2972.

[7] Z. R. Liu, H. P. Xu, Z. Z. Zhang and C. Yang, A Novel Scheme of Constant Current Control Strategy Based on State Feedback Linearization for Buck-derived DC/DC Converter, Proceedings of the CSEE, Vol.37, No.2, 2017, pp. 628-634.

[8] X. Li, Y. L. Li, X. Y. Chang, Nonlinear Control Algorithm for Super Capacitor Energy Storage System Based on Exact Linearization Theory, Transactions of China Electrotechnical Society, Vol.21, No.2, 2016, pp. 12-20.

[9] C. Yang, H. P. Xu, Z. B. Yuan, Z. Q. Xu, Research on Hybrid Three-level Isolated
Bidirectional DC-DC Converter Feedback Linearization Control Under PWM-phaseshifting Control, Power System Technology, Vol.44, No.6, 2020, pp. 2322-2329.

[10] P. P. Singh, B. K. Roy, Microscopic Chaos Control of Chemical Reactor System Using Nonlinear Active plus Proportional Integral Sliding Mode Control Technique, The European Physical Journal Special Topics, Vol.228, No.1, 2019, pp. 169-184.

[11] S. L. Song, W. H. Chen, X. L. Zhang, Fast Second-Order Terminal Sliding Mode Control and its Application in Exoskeleton of Lower Extremities, Control and Decision, Vol.34, No.1, 2019, pp. 162-166.

[12] B. H. Wang, L. Jiang, Backstepping sliding mode control based on exact feedback linearization for bi-directional DC converter in DC microgrid, Power System Protection and Control, Vol.046, No.2, 2018, pp. 43-49.

[13] L. Benadero,R. Cristiano, D. J. Pagano, Nonlinear analysis of interconnected power converters: A case study, IEEE Journal on Emerging and Selected Topics in Circuits and Systems, Vol.5, No.3, 2015, pp. 326-335

[14] F. Wang, B. Chen, C. Lin, Adaptive Neural Network Finite-Time Output Feedback Control of Quantized Nonlinear Systems, IEEE Transactions on Cybernetics, Vol.48, No.6, 2018, pp. 1839-1848.

[15] H. Ma , Y. X . Xie, A Novel Dual closed-Loop Control Strategy based on Sliding-Mode Variable Structure of Vienna-type Rectifier, Transactions of China Electrotechnical Society, Vol.30, No.12, 2015, pp. 143-151.

[16] N. Djagarov, Z. Grozdev, M. Bonev, D. Tsvetanov, G. Enchev, V. Varbev, G. Predoi, J. Djagarova, Power Quality Investigation on a Ship's Power System, International Journal of Circuits, Systems and Signal Processing, Vol.13, 2019, pp. 494-500.

[17] W. Ayrir, M. Ourahou, A. Haddi, DFIG stator reactive and active power control based fuzzy logic, International Journal of Circuits, Systems and Signal Processing, Vol.12, 2018, pp. 262267.

[18] X. X. Hou, X. H. Yang, X. J. Yang, J. G. Jiang, Feedback Linearized on a Sliding Mode Control of PMSM Based Novel Reaching Law, MICROMOTORS, Vol.52, No.12, 2019, pp. 44-48.

\section{Creative Commons Attribution License 4.0 (Attribution 4.0 International, CC BY 4.0)}

This article is published under the terms of the Creative Commons Attribution License 4.0

https://creativecommons.org/licenses/by/4.0/deed.en US 